\title{
Preparation of Copper / Polyaniline Nanocomposite
}

\author{
Zhang Jiapeng $^{\mathrm{a}}$, JiaoLiyong ${ }^{\text {b, }}$, Wu Zhengjie, Li Bo, Zhang Bin \\ Dalian Polytechnic University, Dalian 116034, China \\ a526411202@qq.com , b,*jly366@126.com
}

\begin{abstract}
Keywords: Copper/polyaniline; Nanocomposite; Inverse microemulsion; Core-shell structure Abstract. Using sodium dodecyl sulfate/isoamyl alcohol/n-heptane/water as reaction medium, copper chloride as precursor, Sodium boron hydride as reducing agent, aniline hydrochloride as monomer, copper/polyaniline nanocomposite was prepared by the method of inverse microemulsion polymerization. The nano-composite was characterized by XDS, FTIR and TEM. The result of XDS confirmed that the copper/polyaniline composite contained the main elements of copper, carbon, nitrogen and had no oxygen. It was showed that the polyaniline could effectively prevent the nano copper from being oxidized. FTIR spectra of the material inferred polyaniline was successfully obtained by the polymerization. TEM image showed nanocomposite was core-shell structure, and its average particle size was about $30 \mathrm{~nm}$.
\end{abstract}

\section{Introduction}

Nano copper particles are considered possible replacements for $\mathrm{Au}$ and $\mathrm{Ag}$ particles in the fields of catalysis, lubricant assistant and electric material [1-5]. However, due to suffer oxidation, instability and poor dispersion, the modification research of nano copper is of great necessity [6].

Preparation methods of nano copper particles have high energy ball milling, physical vapor deposition, electrolysis method and aqueous reduction. Aqueous reduction method is of better utility value [7-11]. In this experiment, polyaniline were produced on the surface of nano copper, nano copper particles were be wrapped completely, nano copper composite was obtained with good capability and configuration.

\section{Experiment}

Materials. Copper chloride $\left(\mathrm{CuCl}_{2}\right)$, sodium boron hydride $\left(\mathrm{NaBH}_{4}\right)$, n-heptane $\left(\mathrm{C}_{7} \mathrm{H}_{16}\right)$, isoamyl alcohol $\left(\mathrm{C}_{5} \mathrm{H}_{12} \mathrm{O}\right)$, sodium dodecylsulphate $\left(\mathrm{C}_{12} \mathrm{H}_{25} \mathrm{OSO}_{3} \mathrm{Na}\right)$, anhydrous ethanol, aniline $\left(\mathrm{C}_{6} \mathrm{H}_{7} \mathrm{~N}\right)$, hydrochloric acid (36\%), ammonium peroxydisulfate, carbon tetrachloride. These materials were purchased from Tianjin Guangfu Technology and Development Co., Ltd. All chemicals were of analytical grade. Deionized water was used throughout the experimental work.

\section{Preparation of Copper/Polyaniline Nanocomposite}

\section{Experimental mechanism}

$\mathrm{Cu}^{2+}$ ions were reduced to nano copper with $\mathrm{NaBH}_{4}$, at the same time; nano copper particles were wrapped by $\mathrm{AnH}^{+} \mathrm{Cl}^{2-}$ ions. Doped polyaniline was synthesized with aniline hydrochloride as monomer and ammonium persulfate as initiator. The reaction mechanism was shown in Fig.1.

Fig. 1 presented that homogeneous colloidal particles collided each other, and different colloidal particles also collided and created $\mathrm{Cu}^{0}$; then the newly $\mathrm{Cu}^{0}$ formed nano copper in the water core, relying on the previous $\mathrm{Cu}^{0}$; PANI was synthesized by polymerization under APS. Finally, the core-shell structure copper / polyaniline nanocomposite was prepared with the nano copper as core and PANI as shell. 


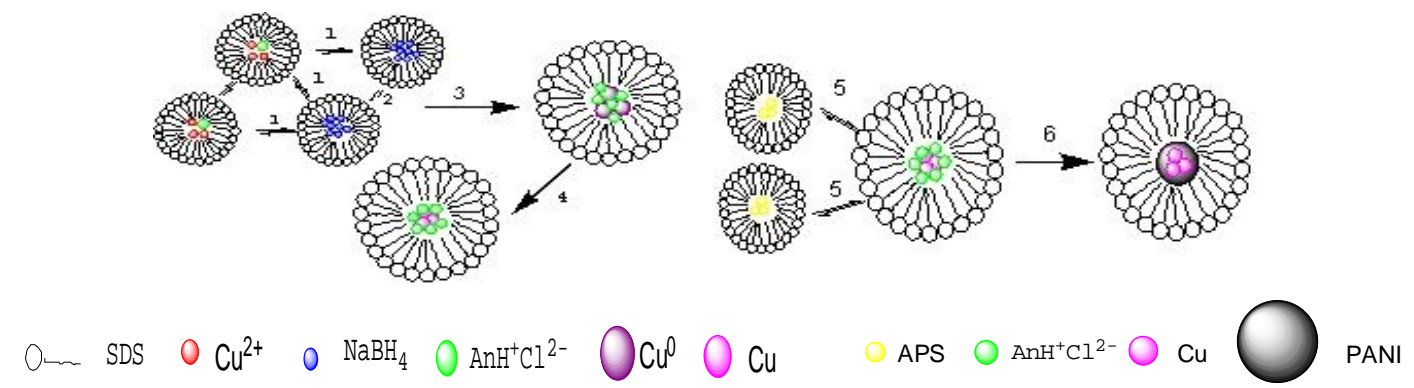

Fig.1 Reaction mechanism of copper / polyaniline nanocomposite

\section{The synthetic process of copper/ polyaniline nanocomposite}

$20 \mathrm{ml}$-heptane, $7 \mathrm{ml}$ iso-amyl alcohol, and $3 \mathrm{~g}$ SDS were added into three-neck flask with $\mathrm{N}_{2}$ atmosphere protection, respectively. Dripped $2.5 \mathrm{ml}$ mixed solution of $0.20 \mathrm{~mol} \mathrm{CuCl}_{2}$ and $0.15 \mathrm{~mol}$ aniline hydrochloride into the flask; then, continued to drip $2.5 \mathrm{ml} 0.40 \mathrm{~mol} \mathrm{NaBH}_{4}$ and $2.5 \mathrm{ml} 0.20 \mathrm{~mol}$ APS solution, and kept the reaction temperature at $0 \sim 4^{\circ} \mathrm{C}$ for $4 \mathrm{~h}$.

The product was demulsified with acetone, centrifugalized at velocity of $8000 \mathrm{r} / \mathrm{min}$ for $10 \mathrm{~min}$, discarded the supernate, utilized anhydrous ethanol to wash the precipitate, and centrifugalized several times. Finally, it was dried in a vacuum stove at room temperature for several days.

\section{Characterization}

The TEM images were obtained by using a transmission electron microscope. The particle dimensions were measured by manual counting from TEM micrographs at $200000 \times$. The XRD patterns of the specimen were displayed using an $\mathrm{X}$-ray diffract meter with $\mathrm{Cu}$ radiation. The particle dimensions were measured by manual counting from X-ray micrographs at $50000 \times$. Chemical structure of copper / polyaniline nanocomposite was characterized by FTIR spectrometer (One B-type, American Perkin Elmer). KBr pellet was prepared and measured in the range from 400 to $4000 \mathrm{~cm}^{-1}$.

\section{Results and discussion}

FTIR Analysis. The chemical structure of copper / polyaniline nanocomposite was measured by FT-IR. The result was shown in Fig.2. The peaks at 2957 and $2851 \mathrm{~cm}^{-1}$ were due to the asymmetric vibration of $-\mathrm{CH}_{2}$; the absorption peak of the $\mathrm{N}=\mathrm{Q}=\mathrm{N}$ (Q: Quinone ring) was at $1610 \mathrm{~cm}^{-1}$, moved to the higher wave number $28 \mathrm{~cm}^{-1}$, Benzene-type structure N-B-N compared to its standard peak blue shift of about $20 \mathrm{~cm}^{-1}$, peak width between $\mathrm{N}=\mathrm{Q}=\mathrm{N}$ and $\mathrm{N}-\mathrm{B}-\mathrm{N}$ was wider obviously. Refer to the standard diagram of polyaniline, the presence of benzene ring and quinone ring in the polyaniline molecular chain was confirmed. Due to induction and conjugate effect, the frequency of gene vibration dropped down, the absorption peaks were shifted to the lower frequency. Thus it was confirmed the resultant products included polyaniline.

X-ray Diffraction Analysis. X-ray diffraction result of the product was shown in Fig3.The obvious copper, carbon, nitrogen peaks confirmed that the resultant product containing these elements. According to the theoretical analysis, elemental copper mainly came from nano copper particles, carbon and nitrogen together constituted a polymer. $\mathrm{Cl}$ element mainly originated from aniline hydrochloride, other metal elements may be caused when the sample of the composite was put into the copper net. No oxygen is contained in the product. It is expected that the nano copper particles covered by polyaniline could not be oxidized to copper oxide. 


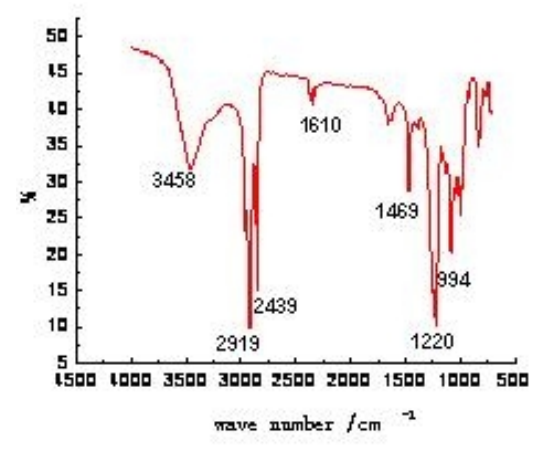

Fig.2 FTIR of product

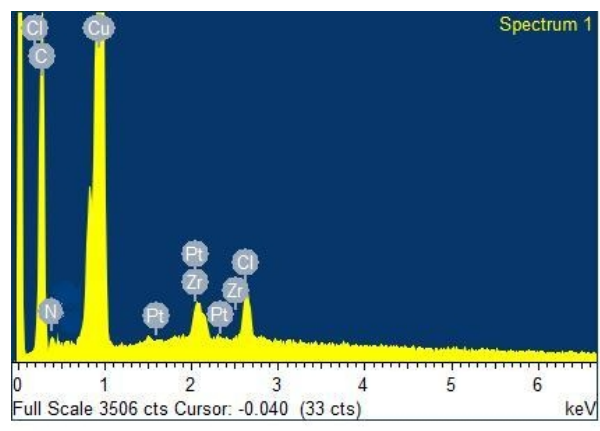

Fig. $3 \mathrm{X}$ diffraction spectrum of product

TEM Analysis. The TEM results are shown in Fig.4. Fig.4a indicated that the particles of the nano composite had the clear core-shell structure, a regular shape and uniform size. Fig.4b showed the low density particles wrapped the high density particles; the particle size was inhomogeneous and formed agglomerate. Figure $4 \mathrm{c}$ exhibited effective response rate of sodium borohydride became very low, and led to decrease of the productivity of nano copper. The product only had the shell without nuclear under the TEM. The essence of this reaction was the interaction collision among micro micelles, which made the exchange of substances to react in the "nano reactor". Exchange rate of materials was relatively slow at low temperature, which could provide a longer intermittent period for the formation of nano copper, conducive to the morphology and growth of nano copper particle. On the contrary, exchange rate increased at high temperature, and activity centers of nano copper also quickened, the sizes of nano copper particles were larger. When more and more "micro-micelle reactor" collided, amount of aniline hydrochloride reunited on the surface of nano-copper, these chains of polyamine were easy to reunite.

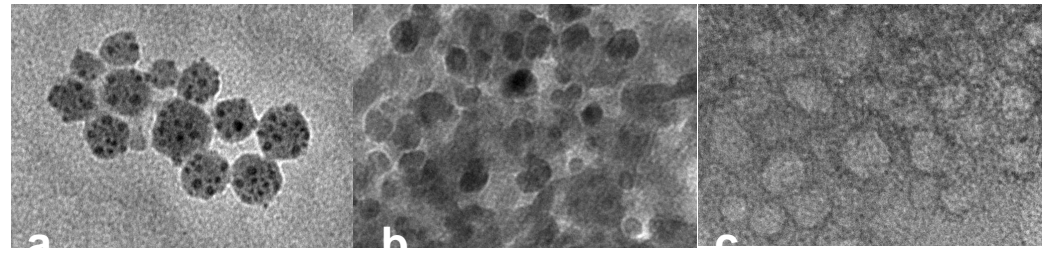

Fig.4 TEM of product at different temperatures $\left(\mathrm{a}: 0^{\circ} \mathrm{C}\right.$; b: $15^{\circ} \mathrm{C}$; c: $30^{\circ} \mathrm{C}$.)

\section{Conclusion}

To isoamyl alcohol / n-heptane / sodium dodecyl sulfate / water as a reaction medium, chloride as the metal precursor, sodium borohydride for reducing agent, aniline hydrochloride as monomer, copper / PANI nano composite was successfully prepared. Copper, carbon, nitrogen were contained in the products has been confirmed by EDS. The copper / PANI was generated by the polymerization process and evaluated by FTIR. TEM images showed that low temperature was good to form a core-shell structure, well-dispersed nano copper.

\section{References}

[1] W.Zhu, S.J. Wang, Y. J. Zhao, W.Yang, F.Z. Qu, Preparation of nanoparticles in W/O reverse micromulsion and its application, China Surfactant Deterg. Cosmet. 6(2005)374-379

[2] R.M. Zhou, M.W. Chen, R.H. Yin, Z. Z. Yu, Research Process of Metallic Nano-particles Conductive Ink, Plating and Finishing.31(2009)16-21. 
[3] X.L.WANG, B.S. XU, Y. XU, P.J. SHI, H.L. YU, Y. ZHAO, The Application of Nano-Cu Additive to Equipments Repairing Technology, China Surface Engineering .S1(2006)134-136.

[4] S. Tarasov, A. Kolubaev, S.Belyaev, eta1. Study of friction reduction by nano-copper additives to motor oil, Wear.252 (2002) 63-69.

[5] L. Lu, M. Sui, K. Lu, Superplastic extensibility of nanocrys-talline copper at room temperature, Science.5457 (2000)1463-1466.

[6] S. B.Kalidindi , U.Sanyal , B. R. Jagirdar, Nanostructured $\mathrm{Cu}$ and $\mathrm{Cu}_{2} \mathrm{O}$ core shell Catalysts for hydrogen generation from ammonia borand, Phys. Chem. Chem. Phys. 38(2008)5780-5874.

[7] L.Y. XU, D.KUANG, Y.D.DENG, the Preparation Technology and Application of Copper Nanoparticles, Materials Review. 27(2013) 37-41.

[8] J.S. HUANG, S. REN, C.W. XIE, Nanocrystalline Powder Copper Prepared by Reduction in Acqueous Solution, Journal of Materials Science \& Engineering.1(2003) 57-59.

[9] Y. QIN, P.Y. ZHANG, J.F. CHEN, Preparation of nanocrystalline copper powders by aqueous reduction, Journal of Beijing University of Chemical Technology 6(2006)86-88.

[10] Q.M. LIU, D.L.ZHOU, Y.Y.YAMAMOTO, R.ICHINO, M.OKIDO, Preparation of Cu nanoparticles with $\mathrm{NaBH}_{4}$ by aqueous reduction method, Trans. Nonferrous Met. Soc.22 (2012) 117123.

[11] B.J. GAO, J.F. GAO, J.Q. ZHOU, Z. GE, Study on Preparation of Ultra fine Nicked Particles by the Method of W/O Microemulsion, J. Inorg. Chem. 7 (2001) 491-495. 